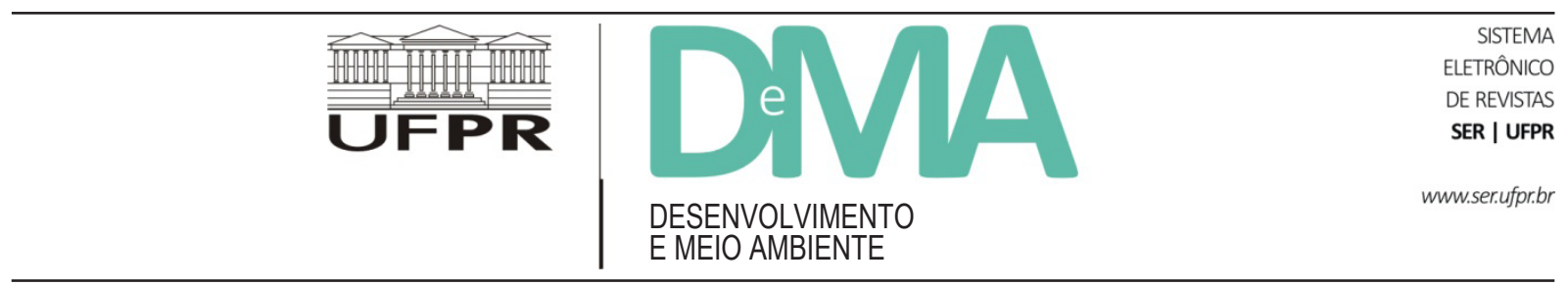

\title{
O futuro dos Pagamentos por Serviços Ambientais no Brasil a partir do novo Código Florestal
}

\section{The Future of Payments for Environmental Services in Brazil through the New Forest Code}

\author{
Marcos Vinicius GODECKE ${ }^{1 *}$, Haide Maria HUPFFER², Iara Regina CHAVES ${ }^{2}$ \\ ${ }^{1}$ Universidade Federal de Pelotas (UFPel), Pelotas, RS, Brasil. \\ ${ }^{2}$ Universidade Feevale, Novo Hamburgo, RS, Brasil. \\ *E-mail de contato: marcosgodecke@gmail.com
}

Artigo recebido em 24 de dezembro de 2013, versão final aceita em 24 de julho de 2014.

RESUMO

Este artigo contextualiza a situação dos programas de Pagamentos por Serviços Ambientais (PSA) no Brasil e discute o seu futuro frente ao Projeto de Lei 792/2007 e suas emendas, em tramitação no Congresso Nacional, e ao novo Código Florestal, a Lei 12.651/2012. Esta Lei, com alterações promovidas pela Lei 12.727/2012, introduz diversos instrumentos econômicos, por meio da criação do "Programa de Apoio e Incentivo à Preservação e Recuperação do Meio Ambiente", inclusive com a instituição de um Mercado Brasileiro de Serviços Ambientais (MBSA). A conclusão é de que não existe sombreamento entre os instrumentos econômicos instituídos pela nova Lei e os propostos pelo referido Projeto de Lei, onde o PSA seria operado a partir da criação de um fundo de âmbito nacional, comparativamente aos programas em andamento no país, constituídos pelas forças de mercado ou por legislações estaduais e municipais. São iniciativas que se complementam na busca da reversão do quadro de depleção dos serviços ecossistêmicos brasileiros.

Palavras-chave: pagamentos por serviços ambientais; código florestal; Brasil.

ABSTRACT This article analyzes the current status of Payments for Environmental Services (PES) programs in Brazil and discusses its future against the Law Project 792/2007 and its amendments in the Congress, and the new Forest Code (law 12.651/2012). This law, with amendments introduced by Law 12.727/2012, introduces several economic instruments by the "Program for Support and Incentive to Environmental Preservation and Restoration" ("Programa de Apoio e Incentivo à Preservação e Recuperação do Meio Ambiente") and the establishment of a market for environmental services, the "Mercado Brasileiro de Serviços Ambientais" (MBSA). The conclusion is that there is no intersection between economic instruments created by this new Law and that Law Project, where the PSA would be operated from the creation of a national fund, in comparison with the programs created by market forces or state and local laws. These initiatives complement each other to revert the depletion framework of Brazilian ecosystem services.

Keywords: payments for environmental services; forest code; Brazil. 


\section{Introdução}

O capítulo décimo da Lei 12.651/2012, com alterações introduzidas pela Lei $12.727 / 2012$, aborda o "Programa de Apoio e Incentivo à Preservação e Recuperação do Meio Ambiente", onde a nova lei introduz mecanismo de Pagamento por Serviços Ambientais (PSA), pelo qual um proprietário rural que não consegue enquadrar-se nas normas de formação das reservas legais poderá comprar do produtor rural os serviços ambientais da sua propriedade, assim compensando legalmente as reservas não constituídas. Pode-se, então, considerar que o PSA está formalmente instituído em legislação federal.

Tramita no Congresso Nacional desde 2007 o Projeto de Lei 792/2007, que já recebeu diversas propostas de emendas, inclusive uma do próprio Poder Executivo - o Projeto de Lei 5.487/2009 -, propondo a criação da Política Nacional de Serviços Ambientais (PNSA). Com efeito, e considerada a importância estratégica para o planeta dos serviços ecossistêmicos prestados no território brasileiro, resulta fácil a verificação de que o PSA estará cada vez mais presente no debate nacional.

Tal fato segue uma tendência mundial, pois os PSA representam um instrumento econômico bastante comum em nível mundial: Landell-Mills e Porras (2002) já identificavam 287 programas de pagamentos por serviços florestais em todo o mundo, envolvendo sequestro de carbono, proteção da biodiversidade, proteção dos mananciais hídricos e da beleza paisagística. No Brasil, desde 2005 os programas PSA estão ganhando força, a partir da iniciativa pioneira do município de Extrema (Minas Gerais) e do programa Produtor de Águas, capitaneado pela Agência Nacional das Águas (ANA).

Tal cenário instiga a aquilatar se a implementação generalizada do PSA no país, combinada com o cumprimento dos demais mecanismos de comando e controle (C\&C) previstos na Lei 12.651/2012, resultará adequada para a preservação dos principais serviços ecossistêmicos propiciados pelas áreas de vegetação, Áreas de Preservação Permanente (APP) e as Áreas de Reserva Legal (RL). Para tanto, o artigo busca apresentar o PSA como instrumento econômico de política ambiental, examinar a legislação federal brasileira sob a ótica do PSA e as principais iniciativas em curso no país. A partir desta construção, discute-se o futuro do PSA no Brasil como dependente de legislações e fundos nacionais ou por ações locais, resultantes de iniciativas voluntárias entre vendedores e compradores de serviços ambientais.

\section{Contextualizando os Pagamentos por Serviços Ambientais}

Os ecossistemas constituem-se em complexos dinâmicos de populações de micro-organismos, plantas e animais, em interações funcionais entre si e com o meio ambiente não vivo. Neles ocorrem diversos processos naturais, resultantes das complexas interações entre os seus componentes bióticos e abióticos por meio das forças universais de matéria e energia. São esses processos naturais que garantem a sobrevivência das espécies no planeta e têm a capacidade de prover produtos e serviços que satisfazem necessidades humanas, direta ou indiretamente. Essas capacidades são definidas como serviços ecossistêmicos quando contribuem para o bem-estar da sociedade (MA, 2003).

Os serviços ecossistêmicos abrangem serviços de provisão, decorrentes da disponibilização dos produtos ambientais, como água e alimentos; serviços de regulação, pela atuação dos processos ecossistêmicos na recuperação e manutenção das condições de equilíbrio ambiental, como na regulação climática e na degradação biológica de poluições; serviços de suporte, como a fotossíntese; e ainda serviços culturais, recreacionais, estéticos e espirituais (Groot, Wilson \& Boumans, 2002; MA, 2003).

Os termos "serviços ecossistêmicos" e "serviços ambientais" são comumente utilizados como sinônimos, porém alguns autores chamam de serviços ecossistêmicos aqueles que ocorrem naturalmente e serviços ambientais os serviços ecossistêmicos acrescidos daqueles promovidos pelo ser humano por meio do manejo ativo dos ecossistemas, com práticas como o plantio agrícola e manejo florestal (Muradian et al., 2010).

As teorias econômicas evidenciam que as atividades humanas geram subprodutos não contabilizados por não terem precificação, denominados externalidades. Estas, quando prejudiciais ao bem-estar humano ou ao ambiente, são classificadas como negativas. Neste 
sentido, a maior compreensão da importância da preservação dos produtos e serviços ecossistêmicos, associada à necessidade de atribuir-se responsabilizações pelas externalidades, levou a formulações como o princípio poluidor-pagador (PPP), o princípio do protetor (ou provedor) recebedor (PPR) e o estímulo à valoração e precificação dos bens e serviços ambientais (Hall \& Lieberman, 2003; Derani, 2008).

O PPP consiste no mandamento destinado ao poluidor para que internalize nos seus custos os valores decorrentes da poluição produzida com sua atividade. Não significa uma licença para poluir mediante o "pagamento" por essa poluição, mas visa evitar a degradação, quando aplicado preventivamente, ou na imputação da responsabilidade pelos danos, quando aplicado posteriormente ao dano. Neste sentido, a Declaração do Rio, de 1992, recomenda às autoridades nacionais a promoção e a internalização dos custos ambientais e o uso de instrumentos econômicos, de modo que o poluidor arque com o custo da poluição. Por sua vez, o PPR visa recompensar os agentes que preservam a natureza, como forma de estimular essas ações e compensar eventuais perdas financeiras decorrentes da não maximização da utilização presente dos recursos naturais, de modo a preservá-los para as gerações futuras. Ambos os princípios visam à proteção do meio ambiente, porém atuam de formas diametralmente opostas: enquanto o PPP busca responsabilizar o poluidor, o PPR procura recompensar o protetor ambiental (ONU, 1992; Fiorillo, 2010).

Para a aplicação prática, estes princípios demandam a valoração dos recursos naturais e de seus serviços, bem como das perdas decorrentes das externalidades a que estiverem sujeitos. A percepção desta necessidade evoluiu na medida em que os recursos naturais, inicialmente vistos como abundantes e acessíveis, passaram a escassos e finitos. Em vista disso, a valoração econômica dos recursos naturais vem evoluindo ao longo das últimas décadas, pela utilização de métodos de valoração dos seus múltiplos usos. Incluem o valor de uso direto; o valor de uso indireto, representado pelas suas externalidades positivas; o valor de opção, resultante das características intrínsecas poderem ser demandadas no futuro em usos diretos ou indiretos, resultando em uma reserva de valor para as gerações futuras; e pelo valor de não uso ou de simples legado e existência, neste caso associado a questões morais, culturais, éticas ou altruístas (Pagiola, Bishop \& Landell-Mills, 2002; Sukhdev, 2008; Motta, 2006).

A precificação do recurso natural pode ocorrer em três níveis. O primeiro é a cobrança pelo valor econômico integral, onde todas as externalidades são incorporadas ao preço do recurso. Como o valor econômico integral é de difícil mensuração, a alternativa pode ser a adoção do preço de financiamento. Neste caso, a cobrança é utilizada para financiar a reparação de danos preexistentes, visando à recuperação da função ecossistêmica e às adequações aos processos de produção ou consumo, de modo que atinjam, num prazo preestabelecido, as metas de uso do recurso natural. De maior abrangência que o financiamento está a adoção do preço de indução, onde a precificação considera não apenas o preço de financiamento, mas alcança a indução dos usuários às práticas sustentáveis (Pérez, Fernández \& Sayer, 2007).

A formatação de princípios de condutas e os métodos de precificação servem como ferramentas para a formulação de instrumentos para as políticas em prol da conservação e uso sustentável dos ecossistemas. Por sua vez, os instrumentos de política ambiental podem ser classificados como: (i) instrumentos de comando e controle (C\&C), a exemplo de legislações estabelecendo níveis máximos para poluições, padrões de condutas ambientais ou proibições e restrições a produtos, atividades e tecnologias; (ii) instrumentos de comunicação ou voluntários, como o estabelecimento de acordos, criação de redes, sistemas de informação ambiental, selos ambientais ou marketing ambiental; e (iii) instrumentos econômicos (IE), baseados tanto no PPP como no PPR (Furlan, 2008; Lustosa, Cánepa \& Young, 2010).

O estímulo ao uso dos IE provém da esperança de que suas aplicações resultem em maior eficiência frente aos tradicionais mecanismos de C\&C. Visam a um posicionamento proativo, em oposição às ferramentas de tutela, que ocorrem post factum, posto que as ações tardias costumam mostrar-se mais dispendiosas e menos eficazes à conservação ambiental (Milaré, 2001; Bobbio, 2007).

Como os aparatos de C\&C existentes muitas vezes não são capazes de realizar uma concreta e incisiva tutela do meio ambiente, resultam diferenciadas as aplicações do PPR como os PSA, visto que sua atuação junto ao 
meio ambiente se dá ante factum. São chamados de PSA os mecanismos pelos quais os beneficiários de serviços ambientais promovem compensações aos prestadores desses serviços. Podem resultar da aplicação pura de IE, por meio de interações voluntárias, ou combinados com instrumentos de $\mathrm{C} \& \mathrm{C}$, no que a literatura chama de policy mix. Os objetivos podem prever a manutenção ou aumento da qualidade dos serviços ecossistêmicos até níveis superiores aos previamente estabelecidos, que ocorreriam sem a compensação. As formas de compensação incluem o pagamento em espécie, realização de infraestrutura, acesso a treinamentos, concessão de direitos de uso da terra, certificação de produtos, etc. $\mathrm{O}$ financiamento às compensações pode ser originário de doações (voluntariado); fundos, inclusive internacionais; cobrança de impostos e taxas pagas pelos beneficiários via instrumentos de $\mathrm{C} \& \mathrm{C}$, entre outros. A interação pode ocorrer diretamente entre provedores e consumidores ou com a interveniência de instituições e governos. Ainda, as negociações podem envolver uma ampla gama de partes, incluindo parceiros de implantação, agricultores, comunidades, contribuintes, consumidores, corporações, governos, etc. (FAO, 2007; Tirado, 2010; Ring \& Schröter-Schlaack, 2011).

Embora de conceituação simples, a implementação do PSA costuma apresentar muitas dificuldades, como as elencadas por Wunder (2006): demanda limitada, decorrente da falta de voluntariedade para estes pagamentos; inexistência de precondições institucionais exigidas pelas partes para a negociação, cumprimento de contratos e garantias para, por exemplo, comunidades pobres e remotas; e dificuldades de comunicação, pois quem propõe os programas de PSA costuma utilizar-se de linguajar inacessível aos povos locais. Na mesma linha, a FAO (2007) constata que os serviços ecossistêmicos surgem de processos complexos, dificultando a definição das ações que efetivamente afetem a sua provisão e a identificação precisa de provedores e beneficiários. Ao tempo em que os beneficiários podem resistir ao pagamento por serviços dos quais não percebam benefícios diretos, está sempre presente a dificuldade para o estabelecimento de mecanismos de valoração, medição, avaliação custo-efetiva e definição de preços.

Um mesmo ecossistema, por abrigar diversos tipos de produtos e serviços ecossistêmicos, permite a coexis- tência de diversos PSA, inclusive de forma combinada, e que podem resultar na criação de mercados, como os relacionados à conservação da biodiversidade, ao sequestro de carbono, à preservação dos mananciais hídricos e à preservação da beleza cênica. Nestes casos, o monitoramento e a quantificação dos serviços ecossistêmicos resultam na emissão de certificados representativos dos serviços ambientais, comercializados em ambientes de mercado, a exemplo dos certificados de reduções de emissões de gases de efeito estufa, comumente chamados de créditos de carbono. Ao tempo em que representam a possibilidade de geração de receitas para os produtores, alavancando a economia de comunidades muitas vezes carentes e isoladas geograficamente, os esquemas de PSA carregam complexidades de operacionalização, demandando a tutela de instituições aparelhadas tecnicamente e com credibilidade entre as partes (Pérez, Fernández \& Sayer, 2007).

Casos de aplicação de PSA vêm proliferando em todo o mundo. Nos anos de 2001 e 2002, Landell-Mills \& Porras (2002) realizaram uma revisão de dados empíricos sobre o desenvolvimento de mercados de PSA, identificando 287 casos em todo o mundo, onde a maioria - 69 casos - estava na América Latina e Caribe, originados pelas políticas agrícolas em países da Organização para a Cooperação e Desenvolvimento Econômico (OCDE) - década de 1980 - e das iniciativas de conservação da floresta, a partir da década de 1990 (FAO, 2007).

Com relação aos PSA da América Latina relacionados à preservação das bacias hidrográficas, os participantes do "III Congreso Latinoamericano de Manejo de Cuencas Hidrográficas", ocorrido no Peru, em 2003, concluíram que, apesar das dificuldades e limitações, os sistemas de PSA apresentam vantagens como: (i) servir como ferramenta para a conscientização dos participantes sobre o valor dos recursos naturais; (ii) facilitar a resolução de conflitos e a construção de consensos entre as partes interessadas; (iii) melhorar a eficiência na alocação dos recursos naturais, sociais e econômicos; (iv) gerar novas fontes de financiamento para a conservação, restauração e valorização dos recursos naturais; (v) criar indicadores de importância para os recursos naturais; (vi) transferir recursos para setores economicamente vulneráveis de ofertantes de serviços ambientais (FAO, 2004). 
Apesar das múltiplas vantagens, a implementação dos PSA no Brasil é modesta quando comparada ao contexto internacional, além de insatisfatória frente à necessidade de preservação dos recursos ambientais do país, levando ao questionamento sobre a adequação da legislação para o fomento destes programas. O próximo tópico revisa o arcabouço legal, procurando trazer elementos sobre sua adequação para o estímulo aos programas de PSA no Brasil.

\section{O Novo Código Florestal sob a ótica dos PSA e as principais iniciativas nacionais}

Analisando-se cronologicamente a legislação ambiental brasileira sob a ótica da utilização de IE de política ambiental, um bom ponto de partida é o decreto 23.793/1934, que instituiu o primeiro Código Florestal brasileiro. Em meio às regras de $\mathrm{C} \& \mathrm{C}$, seu artigo 12 prevê a hipótese de desapropriação de terras para fins de proteção ambiental, quando reconhecida esta necessidade ou conveniência por parte do poder público. Outro instrumento econômico surge no artigo 17, isentando de qualquer imposto as terras com florestas classificadas como "protetoras" pela lei. No seu artigo 98 cria um fundo, o Fundo Florestal, constituído de contribuições e doações de interessados na conservação da floresta, a ser gerido por um Conselho Florestal, instituído no artigo 101 (Brasil, 1934).

O Estatuto da Terra - Lei 4.504/1964 -, publicado ainda no primeiro ano do governo militar, regulava os direitos e obrigações concernentes aos bens imóveis rurais para fins da reforma agrária e políticas agrícolas. Preocupado em ampliar o uso social das terras, nos seus artigos 49 e 50 estabeleceu critérios de regressividade sobre o pagamento do Imposto sobre a Propriedade Territorial Rural (ITR) pela maior utilização da terra na exploração agrícola, pecuária e florestal: previa a concessão de até $45 \%$ de redução do imposto pelo grau de utilização da terra, medido entre a área efetivamente utilizada e a área aproveitável total do imóvel rural. Com isso o governo criou um instrumento econômico via redução tributária para estímulo à maximização do uso da terra. Ficou evidenciado o interesse "desenvolvimentista" vigente à época, onde as áreas com matas naturais eram vistas como economicamente ineficientes, sujeitando seus proprietários à desapropriação para fins de reforma agrária, enquadradas como latifúndios (artigo 20) (Brasil, 1964).

No ano seguinte, o governo militar revogou o antigo Código Florestal e sancionou a Lei 4.771/1965, bastante protetora dos recursos naturais, a exemplo de definir como APP as florestas e demais vegetações presentes nas margens de cursos d'água. Não obstante o minucioso aparato de proteção ambiental então estabelecido, talvez por falta de capacidade fiscalizadora, nota-se que aquela Lei não logrou êxito na proteção ambiental pretendida, principalmente nas regiões onde ocorreram as expansões da fronteira agropecuária em direção à Amazônia, haja vista a depleção ambiental verificada nos recursos florestais verificados no país nas últimas décadas, e em especial naquela região. No tocante aos IE, seus artigos 38 e 39 mantiveram a isenção de ITR sobre áreas de florestas com regime de preservação permanente, presente na Lei 4.504/1964, mas este instrumento legal mostrava a mesma preocupação desenvolvimentista presente naquela lei, ao conceder igual isenção para as florestas plantadas para fins de exploração madeireira, ao tempo em que limitava a $50 \%$ o desconto sobre o ITR da área tributável quando as áreas fossem de florestas nativas. Manteve o Conselho Florestal, mas deixou de legislar sobre o Fundo Florestal. No artigo 41, estabeleceu ao Conselho Monetário Nacional a competência para fixar juros e prazos compatíveis aos financiamentos florestais relacionados com os planos de florestamento e reflorestamento aprovados pelo Conselho Florestal (Brasil, 1965).

Ainda que pouco respeitada, a Lei 4.771/1965 foi objeto permanente de insatisfação por parte de ambientalistas e ruralistas, de modo que sofreu diversas alterações ao longo do tempo. Recentemente, após calorosa discussão no Congresso Nacional, que despertou a atenção da sociedade brasileira, aquela legislação foi substituída pela Lei 12.651, de 25 de maio de 2012. Porém, esta promulgação não satisfez os segmentos ruralistas e ambientalistas, que continuaram discutindo-a tanto no âmbito legislativo como em esferas da sociedade civil. Estas discussões resultaram em alterações, introduzidas pela Lei 12.727, de 17 de outubro de 2012. Não obstante as negociações e a promulgação da lei, o novo Código 
Florestal continua objeto de críticas (Brasil, 2012a; 2012b; Soares-Filho et al., 2014).

Visto sob a ótica das perspectivas do PSA, o novo Código Florestal traz aspectos a serem destacados sob a ótica dos instrumentos econômicos, a começar pelo seu artigo primeiro, ao prever a possibilidade do uso de instrumentos econômicos e financeiros para o alcance dos objetivos da Lei. Entre os princípios elencados no artigo segundo está a "criação e mobilização de incentivos econômicos para fomentar a preservação e a recuperação da vegetação nativa e para promover o desenvolvimento de atividades produtivas sustentáveis". A Lei dedica seus artigos 41 a 50 para disciplinar estes incentivos, no tópico intitulado "Programa de Apoio e Incentivo à Preservação e Recuperação do Meio Ambiente". Os instrumentos deste Programa estão especificados no artigo 41, abrangendo: (I) PSA; (II) instrumentos financeiros e tributários; (III) incentivos à comercialização, inovação e das ações de recuperação, conservação e uso sustentável das florestas. Destes últimos, a lei relaciona a participação preferencial nos programas de apoio à comercialização da produção agrícola e a destinação de recursos para as pesquisas científica e tecnológica relacionadas à melhoria da qualidade ambiental.

Quanto aos instrumentos financeiros e tributários (item II), a Lei prevê: (a) obtenção de crédito agrícola com taxas de juros menores e prazos maiores do que os praticados no mercado; (b) contratação do seguro agrícola em condições melhores; (c) dedução das APP e RL da base de cálculo do ITR; (d) destinação de parte dos recursos arrecadados com a cobrança pelo uso da água para a preservação florestal das bacias hidrográficas; (e) linhas de financiamento para atender iniciativas de preservação voluntária de vegetação nativa, entre outras; e (f) isenção de impostos para os principais insumos e equipamentos utilizados no cercamento das reservas. Além destes, a dedução da base de cálculo do Imposto de Renda do proprietário rural, pessoa física ou jurídica, de parte dos gastos efetuados com a recomposição de RL desmatadas anteriormente a 22 de julho de 2008 e utilização de fundos públicos para concessão de créditos reembolsáveis e não reembolsáveis destinados à compensação ou recuperação das reservas cujo desmatamento seja anterior à data-limite anteriormente citada. Abre, ainda, a possibilidade de diferenciação tributária para empresas que industrializem ou comercializem produtos originários de propriedades que cumpram padrões e limites estabelecidos ou que estejam em processo de cumpri-los (Brasil, 2012a).

Os artigos 42 a 50 apresentam diretrizes para a implementação de PSA por meio da criação de um mercado de serviços ambientais. A Tabela 1 apresenta de forma resumida a operacionalização deste mercado a partir das especificações estabelecidas na Lei.

A introdução do mecanismo de PSA não prevê a utilização de recursos públicos ou fundos, apostando nas forças de mercado para a compatibilização de interesses entre produtores e consumidores de serviços ecossistêmicos. Não obstante a isto, segue o trâmite no Congresso Nacional o Projeto de Lei 792/2007 e suas emendas, em especial o Projeto de Lei 5.487/2009, proposto pelo Ministério do Meio Ambiente. Preveem a criação da Política Nacional de Serviços Ambientais (PNSA) e do Programa Federal de Pagamento por Serviços Ambientais (PFPSA). O programa proposto visa PSA em propriedades rurais de até quatro módulos fiscais, por meio da criação do Fundo Federal de Pagamento por Serviços Ambientais (FFPSA) (Brasil, 2007; 2009).

Paralelamente ao esforço regulatório do Governo Federal, o PSA é realidade no Brasil, instituído por legislações estaduais e municipais, bem como por iniciativas resultantes das forças de mercado. A Tabela 2 cita de forma resumida o conteúdo de algumas das legislações em nível estadual relacionadas ao PSA.

Além dos Estados, diversos municípios brasileiros vêm formulando legislações que criam condições de financiamento ou o pagamento aos prestadores de serviços ambientais. São exemplos a Lei 2.100/2005, de Extrema (MG), instituindo o projeto Conservador das Águas; a Lei 3.545/2006, de Montes Claros (MG), criando o Ecocrédito; a Lei 58/2009, criando o Projeto Oásis em Apucarana (PR); e a Lei 14.933/2009, em São Paulo (SP), prevendo recursos para serviços ambientais (Oliveira Junior, 2010).

O programa Protetor das Águas, principal programa de PSA em curso no Brasil, teve início em 2006, capitaneado pela ANA. Trata-se de um programa de controle da poluição difusa rural, dirigido prioritariamente às bacias hidrográficas de maior importância para o abastecimento urbano. É baseado no PPR e prevê 
TABELA 1 - Características do mercado brasileiro de serviços ambientais previsto na Lei 12.651/2012.

\begin{tabular}{|c|c|c|}
\hline Artigo & Aspecto & Forma de Operacionalização \\
\hline $41 \S 5$ & Âmbito & Nacional e estadual \\
\hline $41 \S 7$ & Beneficiários & Prioritariamente a agricultura familiar \\
\hline 44 & Instrumento & Cota de Reserva Ambiental (CRA) \\
\hline 46 & Área do CRA & Cada CRA corresponderá a 1 (um) hectare \\
\hline 44 & Regime & $\begin{array}{l}\text { Servidão ambiental, perpétua ou temporária (mínimo de } 15 \text { anos) (art. } 9^{\circ} \text {-A da Lei } n^{\circ} \\
6.938 \text {, de } 31 \text { de agosto de } 1981 \text { ) }\end{array}$ \\
\hline 44 & Objeto & Área de RL instituída voluntariamente \\
\hline $\begin{array}{ll}44 \\
45 \S 4 \\
\end{array}$ & Controle & $\begin{array}{l}\text { Na forma de Reserva Particular do Patrimônio Natural - RPPN. Sistema nacional } \\
\text { centralizado }\end{array}$ \\
\hline $44 \S 1$ & Emissão do CRA & $\begin{array}{l}\text { Mediante requerimento do proprietário, após inclusão do imóvel no Cadastro Am- } \\
\text { biental Rural (CAR) e laudo comprobatório }\end{array}$ \\
\hline $44 \S 4$ & CRA sobre reserva legal & Permitida para a vegetação nativa de pequenas propriedades familiares \\
\hline 45 & Emissão do CRA & Por órgão federal do Sistema Nacional do Meio Ambiente (Sisnama) \\
\hline $45 \S 3$ & Averbação & A área correspondente ao CRA deverá ser averbada na matrícula do imóvel \\
\hline $45 \S 4$ & Orgãos estaduais & O órgão federal pode delegar atribuições a órgãos estaduais \\
\hline $45 \S 4$ & Características do instru- & Pode ser transferido ou cancelado. \\
\hline 48 & mento & $\begin{array}{l}\text { Transferência: pode ser onerosa ou gratuita, para pessoa física ou jurídica, mediante } \\
\text { termo assinado pelas partes }\end{array}$ \\
\hline 50 & & $\begin{array}{l}\text { Cancelamento: por solicitação do proprietário rural; automaticamente, em razão de } \\
\text { término do prazo da servidão ambiental; ou por decisão do órgão competente do } \\
\text { Sisnama }\end{array}$ \\
\hline 47 & Registro para negociação & $\begin{array}{l}\text { Encaminhado pelo órgão emitente, no prazo de } 30 \text { (trinta) dias, contado da data da } \\
\text { sua emissão }\end{array}$ \\
\hline 47 & Ambientes de negociação & $\begin{array}{l}\text { Em bolsas de mercadorias de âmbito nacional ou em sistemas de registro e de liqui- } \\
\text { dação financeira de ativos autorizados pelo Banco Central do Brasil }\end{array}$ \\
\hline $48 \S 2$ & Biomas & $\begin{array}{l}\text { A CRA só pode ser utilizada para compensar Reserva Legal de imóvel rural situado } \\
\text { no mesmo bioma da área à qual o título está vinculado }\end{array}$ \\
\hline $48 \S 4$ & $\begin{array}{l}\text { CRA para compensação } \\
\text { da RL }\end{array}$ & Vinculação por averbação na matrícula dos imóveis cedente e beneficiário \\
\hline
\end{tabular}

FONTE: Brasil, 2012a.

pagamentos aos produtores rurais que adotem práticas e manejos conservacionistas. Tem por objetivos: (i) adoção de práticas conservacionistas de solo com finalidade de abatimento efetivo da erosão e da sedimentação; (ii) implantação de sistemas de saneamento ambiental, incluindo abastecimento de água, tratamento de esgotos e coleta de lixo; (iii) implantação e manutenção das APP; e (iv) formalização da reserva legal através de averbação em cartório (ANA, 2009).

O projeto Conservador das Águas, do município de Extrema (MG), serviu como experiência piloto para o Protetor das Águas, pois foi o primeiro a enquadrar-se nas suas normas. A partir de legislação - a lei municipal 2.100/2005 -, o Município associou-se ao projeto da ANA para crescer em recursos e constituiu parcerias, a exemplo do convênio com a ONG The Nature Conservancy (TNC). Em 2007, a Prefeitura de Extrema aprovou junto ao Comitê de Bacia Hidrográfica do Piracicaba, Capivari e Jundiaí (PCJ) a região conhecida como Bairro do Salto, que corresponde a uma área de 4 mil ha, passando a contar com recursos oriundos da cobrança pelo uso da água daquela bacia. Naquela região estão as nascentes do rio Jaguari, um dos formadores do rio Piracicaba, importante tributário do sistema Cantareira, um dos maiores 
TABELA 2 - Legislações estaduais brasileiras relacionadas ao Pagamento por Serviços Ambientais - PSA.

\begin{tabular}{lll}
\hline Estado & Legislação & Conteúdo \\
\hline Acre & Lei 1.277/1999 & $\begin{array}{l}\text { Prevê incentivos aos seringueiros que organizados em associações } \\
\text { prestem serviços ambientais }\end{array}$ \\
\cline { 2 - 3 } & Lei 1.426/2001 & Autoriza o Governo do Estado a regulamentar os serviços ambientais \\
\hline Amazonas & Lei complementar 53/2007 & $\begin{array}{l}\text { Reconhece os serviços ambientais e estabelece base jurídica para per- } \\
\text { mitir o PSA em unidades de conservação }\end{array}$ \\
\hline Espírito Santo & Lei 8.960/2008 & $\begin{array}{l}\text { Dispõe sobre a criação do Fundo Estadual de Recursos Hídricos (FUN- } \\
\text { DÁGUA) }\end{array}$ \\
\cline { 2 - 3 } & Lei 8.995/2008 & Institui o programa de PSA naquele estado \\
\hline Minas Gerais & Lei 17.727/2008 & $\begin{array}{l}\text { Cria incentivos financeiros rurais (bolsa verde) e dispõe sobre política } \\
\text { hídrica, florestal e biodiversidade }\end{array}$ \\
\cline { 2 - 3 } & PL 952/2007 & Visa instituir programa de PSA \\
\hline Paraná & Lei complementar 59/1991 & $\begin{array}{l}\text { Cria o ICMS Ecológico, que destina 5\% do ICMS para municípios com } \\
\text { mananciais e unidades de conservação }\end{array}$ \\
\hline Rio Grande do Sul & PL 3/2004 & $\begin{array}{l}\text { Visa instituir compensação financeira às propriedades com área de pre- } \\
\text { servação permanente }\end{array}$ \\
\hline Rio de Janeiro & PL 1.949/2008 & $\begin{array}{l}\text { Visa criar o programa estadual de certificação de unidades produtivas } \\
\text { familiares }\end{array}$ \\
\hline Santa Catarina & Lei 15.133/2010 & $\begin{array}{l}\text { Institui a Política Estadual de Serviços Ambientais e regulamenta o } \\
\text { Programa Estadual de PSA }\end{array}$ \\
\hline São Paulo & PL 260/2010 & $\begin{array}{l}\text { Visa instituir o “agricultor prestador de serviços ambientais" e criar } \\
\text { incentivos }\end{array}$ \\
\hline
\end{tabular}

FONTE: Oliveira Junior, 2010.

do mundo: abastece cerca de nove milhões de pessoas, cerca da metade da população da região metropolitana de São Paulo (Whately \& Hercowitz, 2008).

Além dos PSA de Extrema e da Bacia PCJ, o projeto Protetor das Águas possui mais seis parcerias: (i) o projeto Pipiripau, na bacia do Ribeirão Pipiripau, localizado no nordeste do Distrito Federal, fazendo divisa com o município de Formosa (GO); (ii) o projeto ProdutorES de Água, em todas as bacias hidrográficas do Espirito Santo, com base na lei 8.995/2008; (iii) o projeto Oásis, instituído em Apucarana (PR) a partir da lei 58/2009, abrangendo as bacias dos rios Ivaí, Pirapó e Tibagi; (iv) o projeto Produtores de Água e Floresta, na microbacia do Rio das Pedras, pertencente à bacia do rio Guandu, no município de Rio Claro (RJ); (v) o projeto Produtor de Água do Balneário Camboriú (SC), na bacia hidrográfica do rio Camboriú; e (vi) o programa Manancial Vivo, instituído pela prefeitura de Campo Grande (MS) em cumprimento ao decreto 11.303/2010, que instituiu o PSA naquele município, em andamento nas bacias hidrográficas de Guariroba e Lajeado (ANA, 2012).

Além do projeto Oásis de Apucarana, da qual é parceira, a Fundação Grupo Boticário de Proteção à Natureza desenvolve, desde 2006, outro projeto de mesmo nome, cujo objetivo é a proteção de remanescentes de mata atlântica e ecossistemas associados, localizados na área de mananciais da Região Metropolitana de São Paulo. O projeto Oásis atua especificamente na bacia hidrográfica da Represa da Guarapiranga e nas Áreas de Proteção Ambiental dos municípios de Capivari-Monos e Bororé-Colônia (Fundação Boticário, 2011).

No Estado do Rio Grande do Sul é desenvolvido o projeto Protetor das Águas, na sub-bacia do arroio Andreas, localizado na bacia hidrográfica do rio Pardo, município de Vera Cruz. O projeto teve início em 2011, numa parceria entre a Universidade de Santa Cruz do Sul (UNISC), Universal Leaf Tabacos, Fundación Al- 
tadis, Prefeitura Municipal de Vera Cruz, Associação dos Fumicultores do Brasil (Afubra), Sindicato das Indústrias de Tabaco (Sinditabaco) e do Comitê da Bacia Hidrográfica do Rio Pardo (Comitê Pardo). Tem como objetivo a proteção de nascentes, remunerando monetariamente os agricultores, participantes voluntários do projeto (Moraes, 2012).

\section{O futuro do PSA no Brasil}

Assim como para as outras áreas de interesse social, os mecanismos regulatórios legais desempenham papel de extrema importância para a sustentabilidade dos recursos florestais do país, no sentido de atuar para a busca do equilíbrio entre a conservação da natureza e o desenvolvimento econômico via atividades agrossilvipastoris. Neste sentido, servem como elementos regulatórios ao artigo 225 da Constituição Federal, atuando na direção do mandamento constitucional de que "todos têm direito ao meio ambiente ecologicamente equilibrado, [...] impondo-se ao Poder Publico e à coletividade o dever de defendê-lo e preservá-lo para a presente e futuras gerações" (Brasil, 1988).

Ocorre que a legislação ambiental de C\&C vigente não vem apresentando a eficiência preconizada pela Constituição Federal, pois se, de um lado, os biomas brasileiros disponibilizam grandes quantidades de serviços ecossistêmicos em níveis local, nacional e global, assim como benefícios ainda desconhecidos para as futuras gerações, de outro, as atuais taxas de desmatamento ameaçam a existência da floresta e trazem uma crescente preocupação internacional com incipientes esforços do Brasil para reduzir este processo.

De acordo com a Pesquisa de Informações Municipais (MUNIC) de 2008, as queimadas, os desmatamentos e os assoreamentos de corpos d'água foram os impactos ambientais mais apontados pelos gestores municipais. Em regiões mais urbanizadas e economicamente mais desenvolvidas, a poluição da água esteve mais presente, além da preocupação com a escassez de água nos municípios das regiões Sul e Nordeste (IBGE, 2008).

Quando mecanismos de C\&C, aplicados isoladamente, não são capazes de impedir a degradação ambiental, de acordo com o conceito do policy mix, pode-se estudar a conveniência da incorporação de outros instrumentos de política ambiental, relacionados aos instrumentos econômicos e educacionais. No tocante aos IE, a revisão do marco regulatório brasileiro mostra que seu uso foi incipiente, limitado à não tributação das APP e RL e à constituição de fundos baseados em doações. Com relação ao uso de mecanismos de PSA, a defasagem do país é grande em relação à experiência internacional, tomados os exemplos de Nova York e Costa Rica, em prática há mais de duas décadas (Isakson, 2002; Pagiola, Bishop \& Landell-Mills, 2002).

Esta distância histórica começou a se reduzir consistentemente somente em 2005, a partir das iniciativas do município de Extrema e da ANA. Desde então, novos programas estão surgindo nas diversas regiões brasileiras, a partir de iniciativas de grandes consumidores de serviços ecossistêmicos, como usinas hidrelétricas e empresas de abastecimento de água, ou por articulação das instituições públicas, via governos e Ministério Público, associados às ONGs e entidades comunitárias.

Além desta vertente, de amplitude local ou estadual, temos o Projeto de Lei 792/2007 e suas emendas, que propõem programas PSA em nível federal, baseados em fundo (FFPSA) e direcionados para pequenas propriedades rurais. Seu avanço no legislativo tem sido obstaculizado pela dificuldade na definição de fontes de arrecadação para a formação do referido fundo. A tramitação do Projeto de Lei poderá ser influenciada pelo interesse do Poder Executivo e pela implementação dos IE introduzidos pelo novo Código Florestal, em especial a instituição do Mercado Brasileiro de Serviços Ambientais.

A análise das proposições apensas ao PL 792/2007 permite perceber que em nada ferem os princípios da Lei 12.651/2012. Ao contrário, são complementares e enriquecedoras, podendo perfeitamente ser incorporadas ao Programa da Lei ou o Programa ser incorporado na Política Nacional de Serviços Ambientais proposta pelo referido projeto.

Por intermédio do Mercado Brasileiro de Serviços Ambientais, o novo Código Florestal permite a compensação de áreas degradadas de reserva legal (as APPs estão excluídas). Além da recomposição da reserva ou regeneração natural da vegetação, as situações de não conformidade podem ser resolvidas pela "compensação" 
através das seguintes alternativas: (I) aquisição de Cotas de Reserva Ambiental; (II) arrendamento de área sob regime de servidão ambiental ou Reserva Legal; (III) doação ao poder público de área localizada no interior de Unidade de Conservação de domínio público pendente de regularização fundiária; (IV) cadastramento de outra área equivalente e excedente à Reserva Legal, em imóvel de mesma titularidade ou adquirida em imóvel de terceiro, com vegetação nativa estabelecida, em regeneração ou recomposição, desde que localizada no mesmo bioma (Brasil, 2012a, artigo 66).

A alternativa (I) oportuniza a criação do Mercado Brasileiro de Serviços Ambientais, onde a vegetação nativa estaria sendo negociada não apenas no sentido econômico (geração de riqueza e distribuição e renda), mas para a manutenção de áreas não preservadas de RL. Neste momento faz-se necessário aguardar como se comportará este mercado frente à oferta e à demanda. Caberá a quem causou o dano analisar a melhor relação de custos versus benefícios de legalizar a área degradada, seja através do reflorestamento com redução da área de produção ou a compensação através da aquisição de CRA. Apesar da sua modernidade e pioneirismo, o mercado de compensações abrirá a possibilidade da não recuperação de RL, pois a compensação não elimina o desmatamento ocorrido, apenas compensa a situação criada.

A introdução do Mercado Brasileiro de Serviços Ambientais poderá servir de referência em nível internacional, pois se trata de mecanismo do tipo cap-and-trade que somente encontra paralelo nos mercados de créditos de carbono. Apesar do pesado ritual relativo à operacionalização e formalização das transações, necessário para reduzir os riscos das negociações, contará com o apoio dos órgãos do Sistema Nacional de Meio Ambiente (Sisnama), que apresentam maturidade operacional e organizacional para tal, além da operacionalização nas bolsas de valores e mercadorias brasileiras, também aptas para o adequado desempenho da nova demanda. Faltou à legislação prever instrumentos de educação ambiental e de comunicação e a divulgação dos novos instrumentos econômicos previstos na Lei. Os segmentos ligados ao ensino podem auxiliar no preenchimento desta lacuna.
A partir do exposto, pode-se depreender que o futuro dos programas de PSA não virá apenas por iniciativas locais e regionais e, também, não decorrerá simplesmente da alocação de recursos formados por fundos em programas nacionais, assim como não dependerá unicamente do sucesso dos instrumentos econômicos constantes do Código Florestal, mas resultará do somatório destas vertentes, estando sua trajetória de evolução fortemente relacionada à percepção social da necessidade de conservação dos serviços ecossistêmicos.

\section{Considerações finais}

À guisa de conclusões, cabe a retomada do questionamento levantado no tópico introdutório: o futuro do PSA no Brasil dependerá de legislações e fundos nacionais ou ocorrerá localmente, por iniciativa voluntária entre vendedores e compradores de serviços ambientais? A atenta observação dos marcos legais existente e proposto, bem como da natureza das iniciativas de PSA em andamento no país, mostram que não apenas o conjunto das atuais vias de evolução do PSA é importante e necessário, como pode ser insuficiente frente ao ritmo de depleção dos serviços ecossistêmicos brasileiros.

A conservação dos serviços ecossistêmicos está contida no conceito de desenvolvimento sustentável, introduzido na Constituição Federal brasileira como direito das presentes e futuras gerações. Para seu alcance, em complemento ao policy mix de instrumentos de controle e econômicos, cabe a intensificação no uso da terceira vertente de políticas ambientais, representada pela educação ambiental, pois as exigências legais e os incentivos econômicos podem não ser suficientes na falta da introjeção dos valores ambientais pela sociedade.

\section{Agradecimentos}

Agradecimento especial ao Conselho Nacional de Desenvolvimento Científico e Tecnológico-CNPq-por possibilitar a realização da pesquisa. 


\section{Referências}

Agência Nacional de Águas (ANA). Programa produtor de água: manual operativo. ANA/SUM, 2009, Brasília-DF. Disponível em: <http://www.ana.gov.br/produagua/>. Acesso em: 30/05/2012.

Programa produtor de água. 2012. Disponível em: $\overline{<\mathrm{http}: / / p r o d u t o r d e a g u a . a n a . g o v . b r / P r i n c i p a l . a s p x}>$. Acesso em: 14/10/2012.

Bobbio, N. Da estrutura à função: novos estudos da teoria do Direito. São Paulo: Manole, 2007.

Brasil. Decreto 23.793, de 23 de janeiro de 1934. Aprova o Código Florestal. Disponível em: $<$ http://www.jusbrasil.com.br/ legislacao/116688/decreto-23793-34>. Acesso em: 28/10/2012.

. Lei 4.504, de 30 de novembro de 1964. Dispõe sobre o Estatuto da Terra, e dá outras providências. Disponível em: <http://www.planalto.gov.br/ccivil_03/leis/L4504.htm>. Acesso em: 23/10/2012.

. Lei 4.771, de 15 de setembro de 1965. Institui o novo Código Florestal. Disponível em: <http://www.planalto.gov.br/ ccivil_03/leis/L4771.htm>. Acesso em: 23/10/2012.

Constituição da República Federativa do Brasil de 1988. Disponível em: <http://www.planalto.gov.br/ccivil_03/constituicao/constituicaocompilado.htm>. Acesso em: 28/10/2012.

Projeto de Lei 792, de 19 de abril de 2007. Projetos de leis e outras proposições. Disponível em: <http://www. camara.gov.br/proposicoesWeb/fichadetramitacao?idProposi cao $=348783>$. Acesso em: 28/10/2012.

Projeto de Lei 5.487/2009, de 24 de junho de 2009. Projetos de leis e outras proposições. Disponível em: <http:// www.camara.gov.br/proposicoesWeb/fichadetramitacao?idPr oposicao=439941>. Acesso em 28/10/2012.

Lei 12.651, de 25 de maio de 2012a. Dispõe sobre a proteção da vegetação nativa e dá outras providências. Disponível em: <http://www.planalto.gov.br/ccivil_03/_Ato20112014/2012/Lei/L12651.htm\#art83>. Acesso em: 23/10/2012.

. Lei 12.727, de 17 de outubro de 2012b. Altera a lei 12.651, de 25 de maio de 2012. Disponível em: < http://www. planalto.gov.br/ccivil_03/_Ato2011-2014/2012/Lei/L12727. htm>. Acesso em: 23/10/2012. b

Derani, C. Direito Ambiental econômico. 3. ed. São Paulo: Saraiva, 2008.
Fiorillo, C. A. P. Curso de Direito Ambiental Brasileiro. 11. ed. São Paulo: Saraiva, 2010.

Food and Agriculture Organization of the United Nations (FAO). Payment Schemes for Environmental Services in Watersheds. Land and Water Discussion Paper 3. Roma, 2004. Disponível em: <ftp://ftp.fao.org/agl/aglw/docs/lwdp3_es.pdf $>$. Acesso em: 14/10/2012.

Paying farmers for environmental services. FAO Agriculture Series n. 38. Roma, 2007. Disponível em: $<$ http:// www.fao.org/docrep/010/a1200e/a1200e00.htm>. Acesso em: $10 / 10 / 2012$.

Fundação Grupo Boticário de Proteção à Natureza. Projeto Oásis. 2011. Disponível em: <http://www.fundacaogrupoboticario.org.br/PT-BR/Paginas/o-que-fazemos/projeto-oasis/ downloads/default.aspx>. Acesso em: 02/10/2012.

Furlan, M. A função promocional do direito no panorama das mudanças climáticas: a ideia de pagamento por serviços ambientais e o princípio do protetor-recebedor. São Paulo, Tese (Doutorado em Direito) - Faculdade de Direito, PUCSP, 2008. Disponível em: <http:/www.sapientia.pucsp.br/tde_arquivos/9/TDE-2008-05-26T07:14:30Z-5421/Publico/Melissa\%20 Furlan.pdf>. Acesso em: 25/05/2012.

Groot, R. S.; Wilson, M. A.; Boumans, R. M. J. A typology for the classification, description and valuation of ecosystem functions, goods and services. Ecological Economics, 41, 393-408, 2002.

Hall, R. E.; Lieberman, M. Microeconomia: princípios e aplicações. São Paulo: Pioneira Thomson Learning, 2003.

Instituto Brasileiro de Geografia e Estatística (IBGE). Pesquisa de Informações Básicas Municipais: Perfil dos Municípios Brasileiros 2008. Disponível em: <http:/www.ibge.gov.br/ home/estatistica/economia/perfilmunic/2008/munic2008.pdf $>$. Acesso em: 29/10/2012.

Isakson, R. S. Payments for environmental services in the Castkill: Socieconomic analysis of the agricultural Strategy in New York City's Wathershed management plan. Ford Foundation y Fundación Prisma, 2002. Disponível em: <http://www. infoandina.org/sites/default/files/recursos/44_Isakson_R.pdf $>$. Acesso em: 11/10/2012.

Landell-Mills, N.; Porras, I. T. Silver bullet or fools' gold? A global review of markets for forest environmental services and their impact on the poor. International Institute for En- 
vironment and Development (IIED), London. March 2002. Disponível em: <http://www.cbd.int/doc/external/iied/iied-silver-report-2002-en.pdf>. Acesso em: 11/10/2012.

Lustosa, M. C. J.; Cánepa, E. M.; Yong, C. E. F. Política ambiental. In: Economia do Meio Ambiente: teoria e prática. Org.: May, P. H. 2. ed. Rio de Janeiro: Elsevier, 2010.

Milaré, E. Direito do ambiente: doutrina, prática, jurisprudência, glossário. São Paulo: Ed. Revista dos Tribunais, 2001.

Millennium Ecosystem Assessment (MA). Ecosystem and human well-being: a framework for assessment. Washington, DC: Island Press, 2003. Disponível em: <http://pdf.wri.org/ ecosystems_human_wellbeing.pdf $>$. Acesso em: 04/10/2012.

Moraes, J. L. A. Pagamento por Serviços Ambientais (PSA) como instrumento de política de desenvolvimento sustentável dos territórios rurais: o Projeto Protetor das Águas de Vera Cruz, RS. Sustentabilidade em Debate, Brasília, 3(1), 43-56, jan./jun. 2012.

Motta, R. S. Economia Ambiental. Rio de Janeiro: Editora FGV, 2006.

Muradian, R.; Corbera, E.; Pascual, U. Kosoy, N.; May, P. H. Reconciling theory and practice: An alternative conceptual framework for understanding payments for environmental services. Ecological Economics, 69, 1202-1208, 2010.

Oliveira Júnior, M. E. Pagamento por Serviços Ambientais: uma alternativa importante para conservar e recuperar as bacias hidrográficas e fornecer água de qualidade à população. Brasília, Artigo (Especialização em Direito do Trabalho), Faculdade Fortium, 2010.

Organização das Nações Unidas (ONU). Declaração do Rio sobre Meio Ambiente e Desenvolvimento. 1992. Disponível em: <http://www.onu.org.br/rio20/img/2012/01/rio92.pdf >. Acesso em: 27/05/2012.

Pagiola, S.; Bishop, J.; Landell-Mills, N. Selling forest environmental services: market-based mechanisms for conserva- tion and development. London-UK: Earthscan Publications Ltd., 2002.

Pérez, M. R.; Fernández, C. G.; Sayer, J. A. Los servicios ambientales de los bosques. Ecosistemas, 16(3), 2007. Disponível em: $<$ http://www.redalyc.org/src/inicio/ArtPdfRed. jsp?iCve $=54016309>$. Acesso em: 10/10/2012.

Ring, I.; Schröter-Schlaack, C. Instrument Mixes for Biodiversity Policies. Policymix Report, 2, 2011, Helmholtz Centre for Environmental Research - UFZ, Leipzig. Disponível em: <http://policymix.nina.no/Portals/policymix/POLICYMIX\%20Report_No\%202_2011.pdf $>$. Acesso em: 12/10/2014.

Soares-Filho, B.; Rajão, R.; Macedo, M.; Carneiro, A.; Costa, W.; Coe, M. Rodrigues, H.; Alencar, A. Cracking Brazil's Forest Code. Science, 344(6182), 363-364, 25 april 2014.

Sukhdev, P. Prefácio. In: A Economia dos Ecossistemas e da Biodiversidade: um relatório preliminar. European Communities, 2008. Disponível em: <http://www.portalodm. com.br/a-economia-dos-ecossistemas-e-da-biodiversidade-um-relatorio-preliminar--bp--428--np--7.html> Acesso em: 19/05/2012.

Tirado, P. S. M. Experiencias de los Mecanismos de Pagos por Servicios Ambientales en las Áreas Naturales Protegidas. Perú. Servicio Nacional de Áreas Naturales Protegidas por el Estado (SERNANP), 2010. Disponível em: <http://www.redlac.org/ profonanpe $\% 20-\% 20$ experiencias $\% 20 \mathrm{de} \% 20$ mecanismos $\% 20$ de\%20psa.pdf>. Acesso em: 10/10/2012.

Whately, M.; Hercowitz, M. Serviços ambientais: conhecer, valorizar e cuidar: subsídios para a proteção dos mananciais de São Paulo. Instituto Socioambiental (ISA), 2008. Disponível em: <http://www.socioambiental.org/banco_imagens/ pdfs/10366.pdf>. Acesso em: 14/10/2012.

Wunder, S. Pagos por Servicios Ambientales: Principios Básicos Esenciales. Centro Internacional de Investigación Forestal (CIFOR), Ocasional Paper N. 42(s), Indonésia, 2006. 